\title{
Inhibiting xCT Improves 5-Fluorouracil Resistance of Gastric Cancer Induced by CD44 Variant 9 Expression
}

\author{
SAWAKO MIYOSHI ${ }^{1}$, HITOSHI TSUGAWA ${ }^{2}$, JUNTARO MATSUZAKI $^{1}$, KENRO HIRATA $^{1}$, \\ HIDEKI MORI ${ }^{1}$, HIDEYUKI SAYA ${ }^{3}$, TAKANORI KANAI ${ }^{1}$ and HIDEKAZU SUZUKI ${ }^{4}$ \\ ${ }^{1}$ Division of Gastroenterology and Hepatology, Department of Medicine, \\ Keio University School of Medicine, Tokyo, Japan; \\ ${ }^{2}$ Department of Biochemistry, Keio University School of Medicine, Tokyo, Japan; \\ ${ }^{3}$ Division of Gene Regulation, Institute for Advanced Medical Research, \\ Keio University School of Medicine, Tokyo, Japan; \\ ${ }^{4}$ Fellowship Training Center and Medical Education Center, Keio University School of Medicine, Tokyo, Japan
}

\begin{abstract}
Background/Aim: Cancer stem cells (CSCs) play a critical role in resistance to chemotherapy. CD44 is a cell surface marker of CSCs. CD44 variant $9(C D 44 v 9)$ interacts with a cystine-glutamate antiporter $(x C T)$ and is an unfavorable predictive factor in gastric cancer. We investigated the impact of CD44v9 expression on 5-fluorouracil (5-FU) resistance and the efficacy of the $x C T$ inhibitor, sulfasalazine (SASP), in improving drug resistance. Materials and Methods: The human gastric cancer cell line MKN28 was transfected with pRc/CMV plasmids encoding human CD44 or CD44v9, which were used for in vitro and in vivo experiments. Results: $C D 44 v 9$ expression results in 5-FU resistance by increasing intracellular glutathione and suppressing the drug-induced production of reactive oxygen species (ROS). SASP improved the drug sensitivity of CD44v9-expressing cells. Conclusion: Inhibition of xCT improved the clinical efficacy of chemotherapy against gastric cancer. CD44v9 expression can be a novel biomarker to predict resistance against 5-FU in gastric cancer.
\end{abstract}

Gastric cancer is the fifth leading cancer and the third most common cause of cancer-related deaths worldwide (1-3). Helicobacter pylori infection causes atrophic gastritis leading to gastric cancer. H. pylori is classified as a class I carcinogen and is estimated to account for about $89 \%$ of

Correspondence to: Hidekazu Suzuki, MD, Ph.D., FACG, AGAF, RFF, Fellowship Training Center and Medical Education Center, Keio University School of Medicine. 35 Shinanomachi, Shinjukuku, Tokyo 160-8582 Japan. Tel: +81 353633914, Fax: +81 353633967, e-mail: hsuzuki.a6@keio.jp

Key Words: Gastric cancer, cancer stem cells, CD44, CD44 variant 9, 5-fluorouracil, xCT inhibitor, sulfasalazine. gastric cancer cases (4). H. pylori produces CagA protein, which is an effector protein of the type IV secretion system and the bacterial oncoprotein implicated in gastric carcinogenesis (5). However, translocated CagA is usually degraded by autophagy in host epithelial cells. In contrast, CagA specifically accumulates within CD44 variant 9 (CD44v9)-expressing cancer stem cells (CSCs) by escaping autophagic degradation (6). Additionally, we recently reported that CAPZA1 functions as a negative regulator of autophagy, and thereby, translocated CagA accumulates in CAPZA1-overexpressing cells. These findings suggest that the presence of CAPZA1-overexpressing cells remaining in the gastric mucosa even after eradication therapy, increases the risk of metachronous gastric cancer (7).

Chemotherapy is one of the main therapeutic options for advanced gastric cancers. Recent studies have demonstrated that CSCs strongly contribute to chemotherapeutic resistance and tumor recurrence in several types of cancers (8-11). CD44, a major adhesion molecule of the extracellular matrix, is one of the cell surface markers of CSCs in many types of solid tumors (12-16). Especially CD44v9 interacts with $\mathrm{xCT}$, a subunit of the glutamate-cystine transporter, and stabilizes xCT leading to increased intracellular levels of reduced glutathione (GSH). This mechanism enables $\mathrm{CD} 44 \mathrm{v} 9$ expressing CSCs to survive under various conditions of stress by suppressing intracellular reactive oxygen species (ROS). GSH induction and ROS suppression via CD44v9$\mathrm{xCT}$ interaction leads to drug resistance against cisplatin (CDDP), which is one of the most widely used platinum drugs (17). Administration of sulfasalazine (SASP), which is a specific inhibitor of xCT-mediated cystine transport, improves the sensitivity of tumors formed by HCT116 cells in nude mice to CDDP (17). It also inhibits growth, invasion, and metastasis in several types of cancers (18-21). In addition to CDDP resistance, fluoropyrimidine resistance in 
gastric cancer is also a critical factor associated with clinical outcomes. Currently, clinical guidelines recommend doublet or triplet platinum/fluoropyrimidine combinations as the first-line of treatment for patients with advanced/metastatic cancer (22-24). Several regimens including these key drugs have been established and 5-fluorouracil (5-FU) is a widely used pyrimidine analog. It is crucial to understand the mechanism of drug resistance against 5-FU for improving the efficacy of available chemotherapy. 5-FU generates mitochondrial ROS via a p53-dependent pathway, leading to tumor cell death (25). Therefore, we hypothesized that CD44v9 expression contributes to the resistance of 5-FU by stabilizing xCT. Here, we showed that CD44v9 expression leads to 5-FU resistance by increasing intracellular GSH and inhibition of xCT improves 5-FU sensitivity of CD44v9expressing cells.

\section{Materials and Methods}

Cell culture and transfection of CD44s and CD44v9 plasmids. The human gastric moderately differentiated tubular adenocarcinoma cell line, MKN28, was cultured in MEM (Gibco, Grand Island, NY, USA) supplemented with $10 \%$ FBS. cDNAs for human $C D 44 s$ and CD44v9 were transfected into pRC/CMV expression plasmid (Invitrogen, Carlsbad, CA, USA). Transfection of plasmids and cell selection were performed as previously described $(6,17)$.

Reagents and anticancer agents. N-acetylcysteine (NAC) (SigmaAldrich, St. Louis, MO, USA) was used as a radical scavenger. 5FU and SASP were purchased from Kyowa Hakko Kogyo (Tokyo, Japan) and Sigma-Aldrich, respectively.

Cytotoxicity assay. Cells were plated into 96-well microplates $\left(5 \times 10^{3}\right.$ cells/well), cultured overnight, and then, treated with NAC, 5-FU, and SASP for 2 days. Cell Titer-Glo luminescence cell viability kit (Promega, Madison, WI, USA) was used according to the manufacturer's instructions.

Apoptosis assay. Cells $\left(1 \times 10^{4}\right.$ cells/well $)$ were treated with 5-FU for 2 days. Cell Death Detection ELISAPLUS kit (Roche Diagnostics, Mannheim, Germany) was used according to the manufacturer's instructions.

Measurement of reactive oxygen species. Cells were exposed to 5-FU and SASP for $24 \mathrm{~h}$ and were then incubated with $10 \mathrm{mM}$ of CM-H2DCFDA (Invitrogen) in HBSS (Gibco) for $60 \mathrm{~min}$ at $37^{\circ} \mathrm{C}$. Cells were dissociated using $1 \mathrm{mM}$ EDTA, and the intensity of DCF fluorescence was quantified by flow cytometry.

Glutathione assay. Cells $\left(2 \times 10^{3}\right.$ cells/well $)$ were cultured overnight and then treated with 5-FU and SASP for $12 \mathrm{~h}$. GSH-Glo Glutathione Assay Kit (Promega) was used according to the manufacturer's instructions.

Xenograft animal model. All animal experiments in the present study were approved by The Keio University Institutional Animal Care and Use Committee. Female NOD/SCID/IL-2R $\gamma$ null (NOG) mice at 8-9 weeks of age (Central Institute for Experimental Animals, Kanagawa,
Japan) were injected subcutaneously $\left(5 \times 10^{6}\right.$ cells/mouse, 5 mice in each group) on day 0 . Physiological saline, $5-\mathrm{FU}(25 \mathrm{mg} / \mathrm{kg}$ of body weight), and SASP solution ( $\mathrm{pH} 8,250 \mathrm{mg} / \mathrm{kg}$ of body weight) were injected intraperitoneally once a day from day 14 to day 18 and from day 21 to day 25 . Tumor volumes were calculated every 7 days by using the equation, $\mathrm{V}\left(\right.$ in $\left.\mathrm{mm}^{3}\right)=\left(\mathrm{A} \times \mathrm{B}^{2}\right) / 2$, where $\mathrm{A}$ is the largest diameter and $\mathrm{B}$ is the diameter perpendicular to $\mathrm{A}$.

Statistical analysis. GraphPad Prism was used for statistical analysis (GraphPad Software, CA, USA). Student's $t$-test was performed to compare two groups. For comparison of more than two groups, oneway analysis of variance and Tukey's multiple comparison post-hoc test were performed. The criterion of statistical significance was set at $p$-value $<0.05$.

\section{Results}

The cytotoxicity of 5-FU was associated with an increase in ROS and a decrease in GSH. 5-FU showed a cytotoxic effect in MKN28 cells in a dose-dependent manner (Figure 1A). 5-FU induced intracellular ROS (Figure 1B). The intracellular level of GSH was significantly decreased by 5-FU treatment (Figure 1C). Addition of NAC significantly improved cell viability of MKN28 cells treated with 5-FU (Figure 1D). These findings demonstrated that intracellular GSH levels and ROS are involved in 5-FU cytotoxicity.

The expression of CD44 variant 9 induced drug resistance against 5-FU. MKN28 cells were transfected with pRc/CMV expression plasmid encoding human CD44s or CD44v9. Representative immunofluorescent stained cells are shown in Figure 2A. The induction of CD44v9, but not CD44s, significantly improved cell viability and reduced the apoptotic rate of MKN28 cells treated with 5-FU (Figure 2B). MKN28-CD44v9 cells showed significant increase in cell viability compared with MKN28-CD44s cells when treated with $4-100 \mu \mathrm{g} / \mathrm{ml}$ of 5-FU (Figure 2C).

The expression of CD44 variant 9 increased intracellular GSH and suppressed 5-FU-induced ROS. Expression of CD44v9, but not CD44s, significantly increased intracellular levels of GSH (Figure 3A). 5-FU treatment significantly reduced intracellular GSH levels in MKN28-CD44s cells similar to MKN28 cells. In contrast, intracellular GSH levels in MKN28-CD44v9 cells did not change even after administration of 5-FU (Figure 3B). The accumulation of intracellular ROS was less in MKN28-CD44v9 cells compared to MKN28-CD44s cells post 5-FU treatment (Figure 3C). These findings suggested that the suppression of ROS via increased GSH levels leads to 5-FU resistance in CD44v9-expressing cells.

Sulfasalazine promoted drug sensitivity of MKN28-CD44v9 cells to 5-FU. In MKN28-CD44s cells, 5-FU increased the intracellular levels of ROS and addition of SASP enhanced 
A

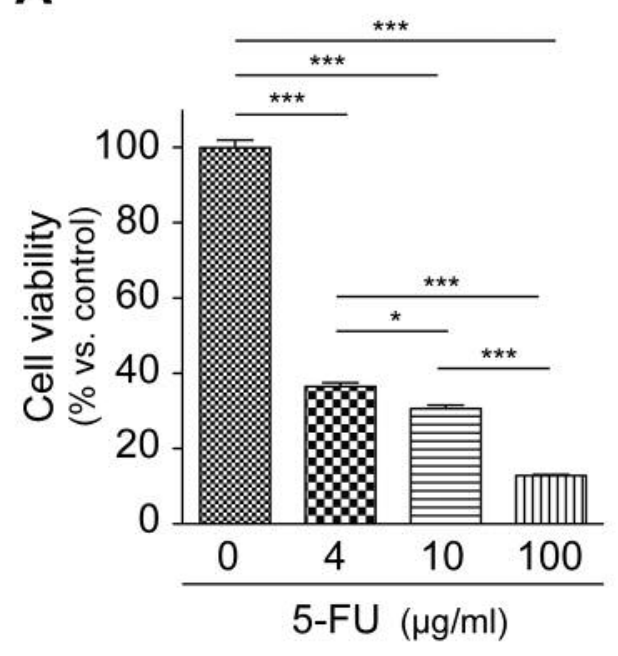

C

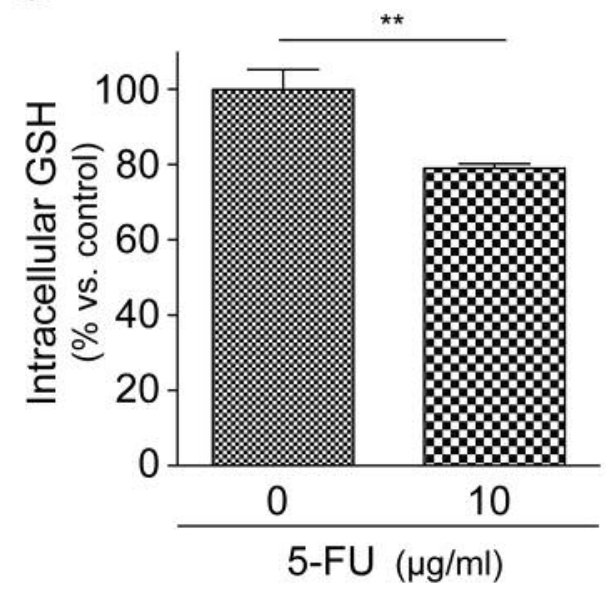

B

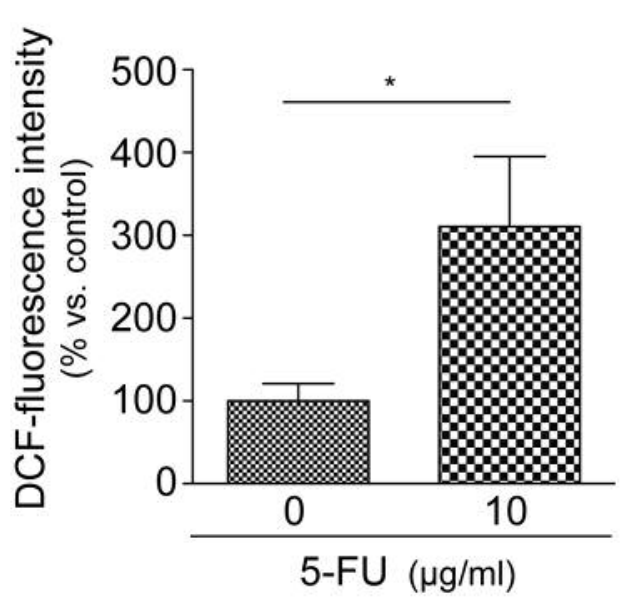

D

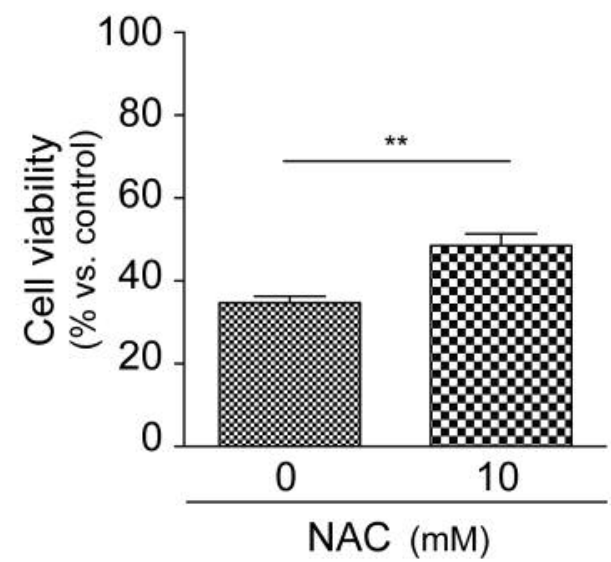

Figure 1. The cytotoxicity of 5-FU is associated with oxidative stress. (A) Changes in cell viability of MKN28 cells upon treatment with 5-FU. (B) $D C F$-fluorescence intensity of MKN 28 cells treated with 5-FU. (C) Intracellular GSH level of MKN28 cells with 5-FU treatment. (D) Cell viability of MKN28 cells treated with NAC and $10 \mu \mathrm{g} / \mathrm{ml}$ of $5-F U . * p<0.05, * * p<0.01, * * * p<0.001$.

this effect. On the other hand, co-treatment of cells with 5FU and SASP, but not 5-FU alone, significantly elevated the levels of 5-FU-induced oxidative stress in MKN28-CD44v9 cells, similar to the levels observed in MKN28-CD44s cells (Figure 4A). Intracellular GSH levels in MKN28-CD44s cells decreased when treated with either 5-FU alone or a combination of 5-FU and SASP. MKN28-CD44v9 cells maintained GSH levels when treated with 5-FU alone but the additional treatment with SASP significantly decreased GSH levels in these cells (Figure 4B). These findings implied that co-treatment with 5-FU and SASP can improve the drug resistance of MKN28-CD44v9 cells against 5-FU. The cell viability of MKN28-CD44v9 cells was significantly higher than that of MKN28-CD44s cells when treated with 10 $\mu \mathrm{g} / \mathrm{ml}$ of $5-\mathrm{FU}$ along with 0,100 and $200 \mu \mathrm{M}$ of SASP, while there was no difference in cell viability between MKN28-CD44v9 and MKN28-CD44s cells with $300 \mu \mathrm{M}$ of SASP (Figure 4C). These results suggested that a sufficient local concentration of SASP can have an adjuvant potential.

Sulfasalazine improved the anti-tumor efficacy of 5-FU in vivo. Mice were injected with MKN28-CD44s or MKN28CD44v9 cells and subsequently treated with vehicle (control group), 5-FU (5-FU group), or 5-FU and SASP (5-FU+SASP group) (Day 0). The tumor volumes were measured on days 14, 21, and 28 (Figure 5A). Among the tumors formed by 


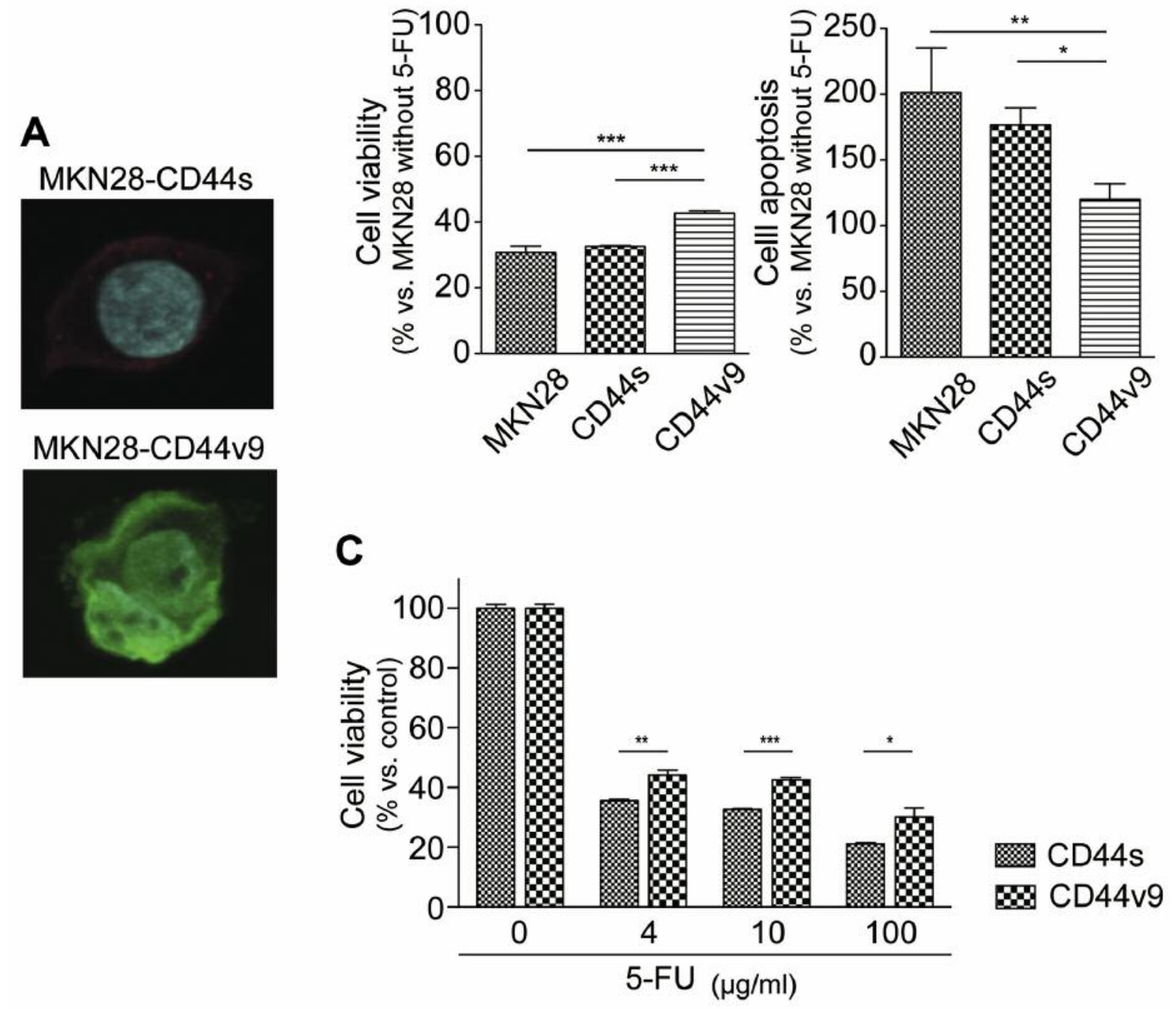

B

Figure 2. CD44v9 transfection induced 5-FU resistance in MKN28 cells. (A) Fluorescence immunocytochemistry of MKN 28 cells transfected with $C D 44 s$ and CD44v9. Alexa Fluor 568-conjugated goat anti-mouse IgG and Alexa Fluor 488-conjugated goat anti-rat IgG antibody were used as secondary antibodies for anti-CD44 antibody and anti-CD44v9 antibody, respectively. (B) Changes in cell viability and cell apoptosis rate in MKN28, MKN28-CD44s, and MKN28-CD44v9 cells treated with $10 \mu \mathrm{g} / \mathrm{ml} 5-\mathrm{FU}$. (C) The difference in cell viability between MKN28-CD44s and MKN28CD44v9 cells treated with 5-FU. *p<0.05,**p<0.01, ***p<0.001.

MKN28-CD44s cells, the tumor volume in 5-FU+SASP group was significantly smaller compared to the control group on day 21 . In addition, tumors were significantly smaller in both 5-FU group and 5-FU+SASP group compared to the control group on day 28 (Figure 5B). In contrast, among the tumors formed by MKN28-CD44v9 cells, 5-FU+SASP group showed smaller tumor volume when compared to both control group and 5-FU group on days 21 and 28 (Figure 5C). These findings demonstrated that tumors of MKN28-CD44v9 cells are 5-FU resistant, but, SASP sensitized cells to 5-FU.

\section{Discussion}

The present study demonstrated that CD44v9 induced drug resistance against 5-FU by increasing intracellular GSH levels and suppressing intracellular ROS levels. Inhibiting xCTmediated cystine transport by SASP improved the drug resistance of CD44v9-expressing tumors against 5-FU both in vitro and in vivo. We previously reported that the interaction between $\mathrm{CD} 44 \mathrm{v} 9$ and $\mathrm{xCT}$ induces drug resistance against CDDP via enhanced anti-oxidant defense system and that SASP improves this resistance (17). Given that fluoropyrimidine (e.g. 

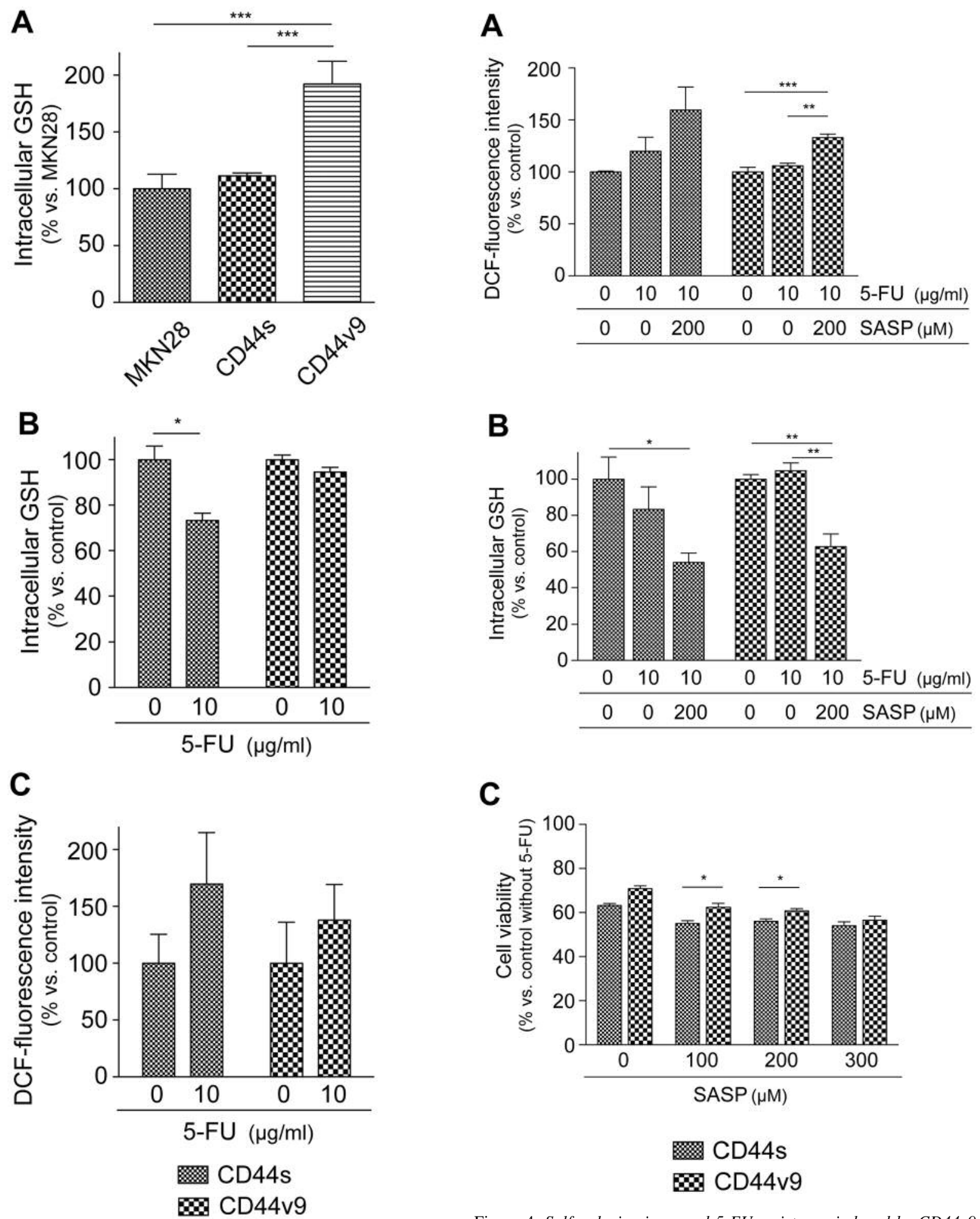

Figure 3. $C D 44 v 9$ promoted the antioxidant defense mechanism in cancer cells. (A) Intracellular GSH level in MKN28, MKN-CD44s, and $M K N-C D 44 v 9$ cells. (B) Changes in intracellular GSH level in $M K N$ $C D 44 s$ and $M K N-C D 44 v 9$ cells treated with 5-FU. (C) Changes in $D C F$-fluorescence intensity in $M K N-C D 44$ s and $M K N-C D 44 v 9$ cells treated with $5-F U . * p<0.05, * * * p<0.001$. 

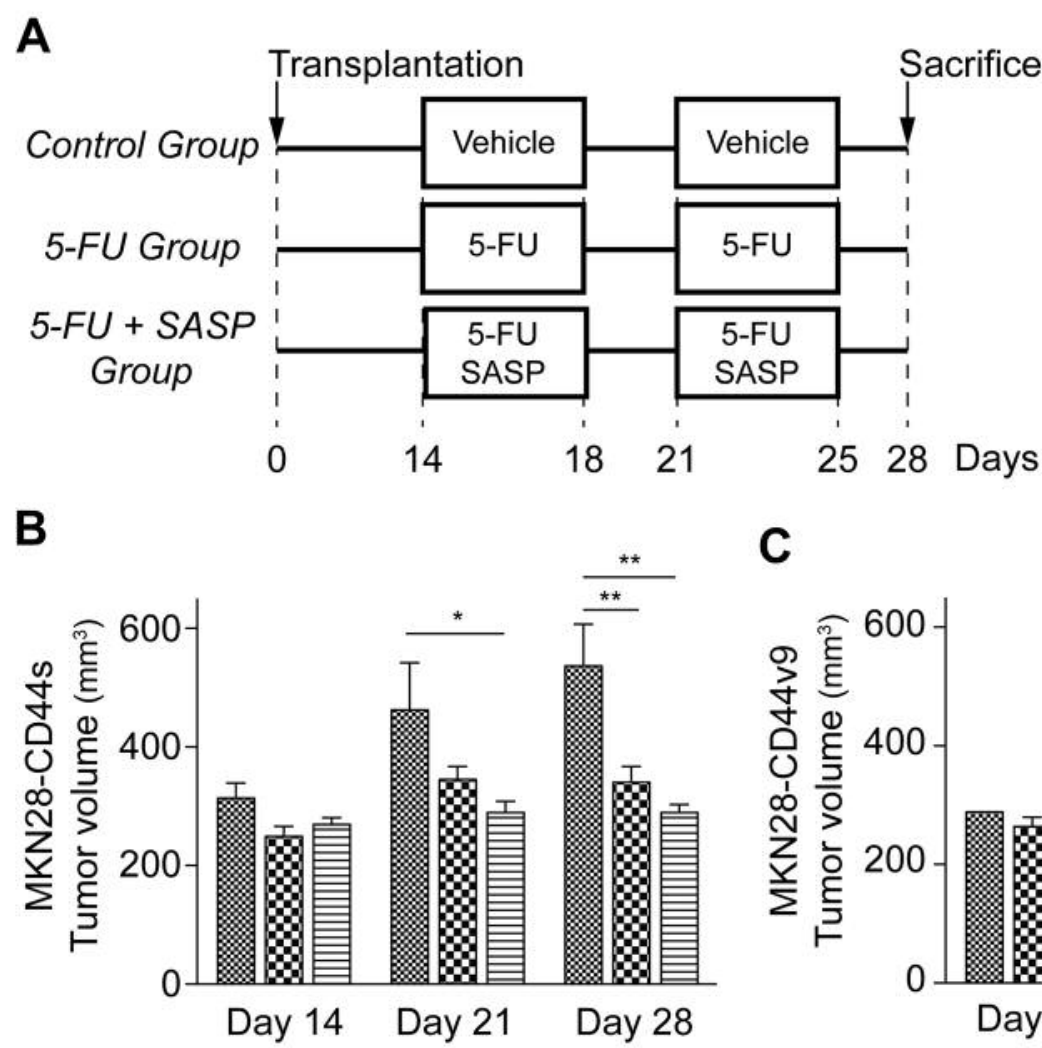

C
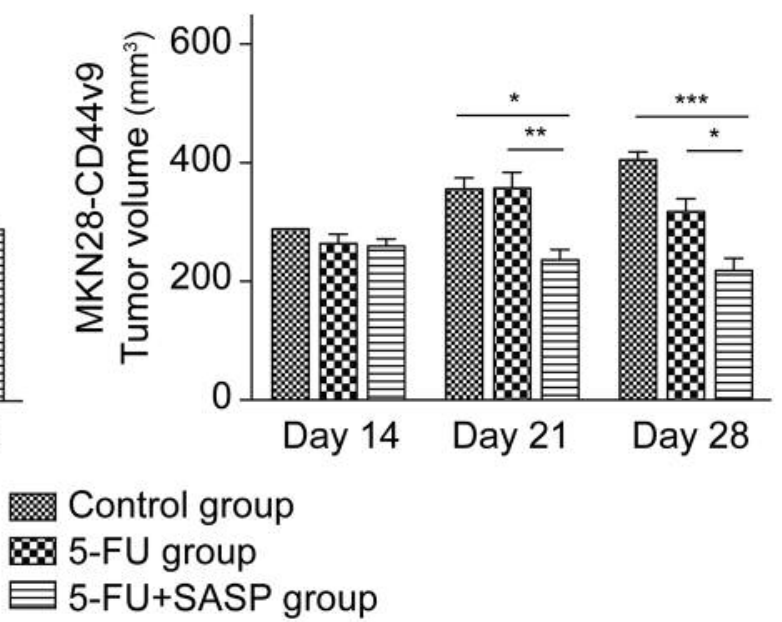

Figure 5. Sulfasalazine improved the anti-tumor efficacy of 5-FU in a xenograft mouse model. (A) Study design using NOD/SCID/IL-2R $\gamma$ null (NOG) mice. (B) Tumor volumes in MKN28-CD44s transplanted mice treated with vehicle, 5-FU or 5-FU plus SASP. (C) Tumor volumes in MKN28-CD44v9 transplanted mice treated with vehicle, 5-FU or 5-FU plus SASP. * $p<0.05$, ** $p<0.01$, *** $p<0.001$.

5-FU) and platinum (e.g. CDDP) are key chemotherapeutic drugs for gastric cancer, our findings suggest that an adjuvant therapy targeting $\mathrm{CD} 44 \mathrm{v} 9-\mathrm{xCT}$ axis can be promising to improve chemotherapy outcomes for gastric cancer.

Since the increase of ROS is common in many pathways leading to cell death (26), the expression of CD44v9 may play a crucial role in the survival of cancer cells against various intrinsic and extrinsic stimuli not only in gastric cancer but also in other cancers. It has been shown that the expression of CD44v in breast cancer cells resulted in enhanced lung colonization and enhanced ROS defense (27). Metastatic sites are new environments for cancer cells, and cells need to survive under microenvironmental stress (28). CD44v may contribute to the survival and colonization of metastatic cells by neutralizing oxidative stress. We demonstrated that epithelial splicing regulatory protein 1 regulates the expression of $\operatorname{CD} 44 \mathrm{v}$, and the epithelial splicing regulatory protein $1-\mathrm{CD} 44 \mathrm{v}-\mathrm{xCT}$ axis is a potential therapeutic target for prevention of metastasis (27). We also reported that the expression of CD44v9 in primary gastric cancer can be a predictive marker for recurrence after curative endoscopic submucosal dissection. Importantly, we found that CD44v9 expression is an independent predictive factor, regardless of the severity of gastric atrophy (29). Our findings suggest that the expression of CD44v9 determines the aggressive behavior of gastric cancer cells. A study on head and neck squamous cell carcinoma reported that concurrent chemoradiotherapy for advanced lesions induced the expression of CD44v9, which was associated with poor prognosis (30). This finding implies that the expression of CD44v9 results in resistance to not only chemotherapy but also radiation therapy. This is because the mechanism of the efficacy of radiotherapy is thought to be the production of ROS (31, 
32). Furthermore, a recent study demonstrated that CD44v9 expression in primary hepatocellular carcinomas in hepatitis $\mathrm{C}$ virus positive patients was associated with poor overall and recurrence-free survival, younger-age, and poor histological tumor differentiation. It was also suggested that CD44v9-positive cells have increased invasion activity (33). These findings imply that targeting CD44v9-xCT axis and intervening the anti-ROS defense mechanism of cancer cells can be a novel adjuvant therapy for various cancers.

In the present study, we used SASP, a specific inhibitor of xCT-mediated cystine transport, and showed its efficacy to improve the drug sensitivity of CD44v9-expressing cancer cells to 5-FU. SASP has been widely used in clinical settings for patients with rheumatoid arthritis and ulcerative colitis, although, the mechanism as to how SASP exerts its therapeutic effect in these diseases remains unclear. SASP is a pro-drug composed of 5-aminosalicylic acid (5-ASA) linked to sulfapyridine through an azo bond (34). It is absorbed in the small intestine only partially because of low solubility and poor permeability (35). The bioavailability of SASP is thought to be less than $15 \%$ (36). The remainder is reduced to sulfapyridine and 5-ASA by bacterial azoreductase $(37,38)$. For SASP to be used in clinical application, several questions arise: (i) Will a tolerable dose of SASP, administered orally, achieve the required concentration in human tumor tissues? (ii) Are there any other efficient and safe routes for administration of SASP to achieve a sufficient concentration? Due to low bioavailability and several known adverse effects of SASP, the development of a novel $\mathrm{xCT}$ inhibitor that is more tolerable with high efficacy is desired.

\section{Acknowledgements}

This work was supported by a Grant-in-Aid for Scientific Research B (16H05291, to HS), from the Japan Society for the Promotion of Sciences (JSPS), and MEXT-Supported Program for the Strategic Research Foundation at Private Universities (S1411003, to HS).

\section{References}

1 Balakrishnan M, George R, Sharma A and Graham DY: Changing trends in stomach cancer throughout the world. Curr Gastroenterol Rep 19: 36, 2017

2 Graham DY: Helicobacter pylori update: gastric cancer, reliable therapy, and possible benefits. Gastroenterology 148: 719-731 e713, 2015 .

3 Torre LA, Bray F, Siegel RL, Ferlay J, Lortet-Tieulent J and Jemal A: Global cancer statistics, 2012. CA Cancer J Clin 65: 87-108, 2015.

4 Plummer M, Franceschi S, Vignat J, Forman D and de Martel C: Global burden of gastric cancer attributable to Helicobacter pylori. Int J Cancer 136: 487-490, 2015.

5 Hatakeyama M: Helicobacter pylori CagA and gastric cancer: a paradigm for hit-and-run carcinogenesis. Cell Host Microbe 15: 306-316, 2014
6 Tsugawa H, Suzuki H, Saya H, Hatakeyama M, Hirayama T, Hirata K, Nagano O, Matsuzaki J and Hibi T: Reactive oxygen species-induced autophagic degradation of Helicobacter pylori CagA is specifically suppressed in cancer stem-like cells. Cell Host Microbe 12: 764-777, 2012.

7 Tsugawa H, Mori H, Matsuzaki J, Sato A, Saito Y, Imoto M, Suematsu M and Suzuki H: CAPZA1 determines the risk of gastric carcinogenesis by inhibiting Helicobacter pylori CagAdegraded autophagy. Autophagy 10: 1-17, 2018.

8 Cazet AS, Hui MN, Elsworth BL, Wu SZ, Roden D, Chan CL, Skhinas JN, Collot R, Yang J, Harvey K, Johan MZ, Cooper C, Nair R, Herrmann D, McFarland A, Deng N, Ruiz-Borrego M, Rojo F, Trigo JM, Bezares S, Caballero R, Lim E, Timpson P, O'Toole S, Watkins DN, Cox TR, Samuel MS, Martin M and Swarbrick A: Targeting stromal remodeling and cancer stem cell plasticity overcomes chemoresistance in triple negative breast cancer. Nat Commun 9: 2897, 2018.

9 Diehn M, Cho RW and Clarke MF: Therapeutic implications of the cancer stem cell hypothesis. Semin Radiat Oncol 19: 78-86, 2009.

10 Hermann PC and Sainz B Jr.: Pancreatic cancer stem cells: A state or an entity? Semin Cancer Biol, 2018. doi: 10.1016/j.semcancer.2018.08.007. [Epub ahead of print]

11 McDermott SC, Rodriguez-Ramirez C, McDermott SP, Wicha MS and Nor JE: FGFR signaling regulates resistance of head and neck cancer stem cells to cisplatin. Oncotarget 9: 2514825165, 2018.

12 Al-Hajj M, Wicha MS, Benito-Hernandez A, Morrison SJ and Clarke MF: Prospective identification of tumorigenic breast cancer cells. Proceedings of the National Academy of Sciences 100: 6890-6890, 2003.

13 Collins AT, Berry PA, Hyde C, Stower MJ and Maitland NJ: Prospective identification of tumorigenic prostate cancer stem cells. Cancer Res 65: 10946-10951, 2005.

14 Dalerba P, Dylla SJ, Park IK, Liu R, Wang X, Cho RW, Hoey T, Gurney A, Huang EH, Simeone DM, Shelton AA, Parmiani G, Castelli C and Clarke MF: Phenotypic characterization of human colorectal cancer stem cells. Proc Natl Acad Sci USA 104: 10158-10163, 2007.

15 Li C, Heidt DG, Dalerba P, Burant CF, Zhang L, Adsay V, Wicha M, Clarke MF and Simeone DM: Identification of pancreatic cancer stem cells. Cancer Res 67: 1030-1037, 2007.

16 Prince ME, Sivanandan R, Kaczorowski A, Wolf GT, Kaplan MJ, Dalerba P, Weissman IL, Clarke MF and Ailles LE: Identification of a subpopulation of cells with cancer stem cell properties in head and neck squamous cell carcinoma. Proc Natl Acad Sci USA 104: 973-978, 2007.

17 Ishimoto T, Nagano O, Yae T, Tamada M, Motohara T, Oshima H, Oshima M, Ikeda T, Asaba R, Yagi H, Masuko T, Shimizu T, Ishikawa T, Kai K, Takahashi E, Imamura Y, Baba Y, Ohmura M, Suematsu M, Baba $\mathrm{H}$ and Saya H: CD44 variant regulates redox status in cancer cells by stabilizing the XCT subunit of system xc(-) and thereby promotes tumor growth. Cancer Cell 19: 387-400, 2011.

18 Chen RS, Song YM, Zhou ZY, Tong T, Li Y, Fu M, Guo XL, Dong LJ, He X, Qiao HX, Zhan QM and Li W: Disruption of $\mathrm{xCT}$ inhibits cancer cell metastasis via the caveolin-1/betacatenin pathway. Oncogene 28: 599-609, 2009.

19 Gout PW, Buckley AR, Simms CR and Bruchovsky N: Sulfasalazine, a potent suppressor of lymphoma growth by inhibition of the $\mathrm{x}(\mathrm{c})$ - cystine transporter: a new action for an old drug. Leukemia 15: 1633-1640, 2001. 
20 Lo M, Ling V, Low C, Wang YZ and Gout PW: Potential use of the anti-inflammatory drug, sulfasalazine, for targeted therapy of pancreatic cancer. Curr Oncol 17: 9-16, 2010.

21 Lo M, Ling V, Wang YZ and Gout PW: The xccystine/glutamate antiporter: a mediator of pancreatic cancer growth with a role in drug resistance. Br J Cancer 99: 464-472, 2008.

22 Ajani JA, D'Amico TA, Almhanna K, Bentrem DJ, Chao J, Das P, Denlinger CS, Fanta P, Farjah F, Fuchs CS, Gerdes H, Gibson M, Glasgow RE, Hayman JA, Hochwald S, Hofstetter WL, Ilson DH, Jaroszewski D, Johung KL, Keswani RN, Kleinberg LR, Korn WM, Leong S, Linn C, Lockhart AC, Ly QP, Mulcahy MF, Orringer MB, Perry KA, Poultsides GA, Scott WJ, Strong VE, Washington MK, Weksler B, Willett CG, Wright CD, Zelman D, McMillian N and Sundar H: Gastric Cancer, Version 3.2016, NCCN Clinical Practice Guidelines in Oncology. J Natl Compr Canc Netw 14: 1286-1312, 2016.

23 Japanese Gastric Cancer A: Japanese gastric cancer treatment guidelines 2014 (ver. 4). Gastric Cancer 20: 1-19, 2017.

24 Smyth EC, Verheij M, Allum W, Cunningham D, Cervantes A, Arnold D and Committee EG: Gastric cancer: ESMO Clinical Practice Guidelines for diagnosis, treatment and follow-up. Ann Oncol 27: v38-v49, 2016.

25 Hwang PM, Bunz F, Yu J, Rago C, Chan TA, Murphy MP, Kelso GF, Smith RA, Kinzler KW and Vogelstein B: Ferredoxin reductase affects p53-dependent, 5-fluorouracil-induced apoptosis in colorectal cancer cells. Nat Med 7: 1111-1117, 2001.

26 Nagano O, Okazaki S and Saya H: Redox regulation in stemlike cancer cells by CD44 variant isoforms. Oncogene 32: 51915198, 2013.

27 Yae T, Tsuchihashi K, Ishimoto T, Motohara T, Yoshikawa M, Yoshida GJ, Wada T, Masuko T, Mogushi K, Tanaka H, Osawa T, Kanki Y, Minami T, Aburatani H, Ohmura M, Kubo A, Suematsu M, Takahashi K, Saya H and Nagano O: Alternative splicing of CD44 mRNA by ESRP1 enhances lung colonization of metastatic cancer cell. Nat Commun 3: 883, 2012.

28 Chiang AC and Massague J: Molecular basis of metastasis. N Engl J Med 359: 2814-2823, 2008.

29 Hirata K, Suzuki H, Imaeda H, Matsuzaki J, Tsugawa H, Nagano $\mathrm{O}$, Asakura K, Saya H and Hibi T: CD44 variant 9 expression in primary early gastric cancer as a predictive marker for recurrence. Br J Cancer 109: 379-386, 2013.
30 Aso $\mathrm{T}$, Matsuo M, Kiyohara $\mathrm{H}$, Taguchi K, Rikimaru F, Shimokawa M, Segawa Y, Higaki Y, Umeno H, Nakashima T and Masuda M: Induction of CD44 variant 9-expressing cancer stem cells might attenuate the efficacy of chemoradioselection and Worsens the prognosis of patients with advanced head and neck cancer. PLoS One 10: e0116596, 2015.

31 Hill RP, Marie-Egyptienne DT and Hedley DW: Cancer stem cells, hypoxia and metastasis. Semin Radiat Oncol 19: 106-111, 2009.

32 Spitz DR, Azzam EI, Li JJ and Gius D: Metabolic oxidation/ reduction reactions and cellular responses to ionizing radiation: a unifying concept in stress response biology. Cancer Metastasis Rev 23: 311-322, 2004.

33 Kakehashi A, Ishii N, Sugihara E, Gi M, Saya H and Wanibuchi $\mathrm{H}$ : CD44 variant 9 is a potential biomarker of tumor initiating cells predicting survival outcome in hepatitis $\mathrm{C}$ virus-positive patients with resected hepatocellular carcinoma. Cancer Sci 107: 609-618, 2016.

34 Naruhashi K, Kamino A, Ochi E, Kusabiraki E, Ueda M, Sugiura S, Nakanishi $\mathrm{H}$ and Shibata N: Absorption process of salazosulfapyridine in human intestinal epithelial cells and rat intestine. Clin Pharmacol Biopharm 5: 4, 2016.

35 Yazdanian M, Glynn SL, Wright JL and Hawi A: Correlating partitioning and caco-2 cell permeability of structurally diverse small molecular weight compounds. Pharm Res 15: 1490-1494, 1998.

36 Klotz U: Clinical pharmacokinetics of sulphasalazine, its metabolites and other prodrugs of 5-aminosalicylic acid. Clin Pharmacokinet 10: 285-302, 1985.

37 Houston JB, Day J and Walker J: Azo reduction of sulphasalazine in healthy volunteers. Br J Clin Pharmacol 14: 395-398, 1982.

38 Peppercorn MA and Goldman P: The role of intestinal bacteria in the metabolism of salicylazosulfapyridine. J Pharmacol Exp Ther 181: 555-562, 1972. 